\title{
Catastrophic Effects of Out-of-Pocket Payments for Health Care Using Synthetic Panel Data
}

\author{
Shiva Raj Adhikari ${ }^{1}$ PhD and Vishnu Prasad Sapkota ${ }^{2}$ \\ ${ }^{1}$ Associate Professor, Tribhuvan University, Patan Multiple Campus, Nepal \\ ${ }^{2}$ Institute for Nepal Environment and Health System Development (INEHD), \\ Kathmandu Nepal
}

\begin{abstract}
Panel data can provide more accurate information about the movement of catastrophic payments. The study measures dynamics of catastrophic payment by utilizing recently developed method of creating synthetic panel from two cross-sectional data. It is interested to estimate percentage of households that faced catastrophic health expenditure in first period but didn't face it in second period. Catastrophic payment is defined as OOP payments as a share of total non-food consumption. The threshold for catastrophic health expenditure for non-food expenditure has been set $15 \%$ to $50 \%$. The findings related to the movement of households from catastrophic health expenditure to non-catastrophic health expenditure and vice versa between the period of 2004 and 2011. Probability of percentage population faced catastrophic impact due to medicine costs in the first period and in the second period is decreasing from 20.1 per cent to 0.01 percent as increased in threshold $15 \%$ to $50 \%$. Similarly, probability of catastrophic impact in the first period but not in the second period is decreasing from 3.1 per cent to 0.00 percent as increased in threshold $15 \%$ to 50\%. Probability of not having catastrophic impact in the first period but catastrophic impact in the second period is decreasing from 17.2 per cent to 1.9 percent as increased in threshold $15 \%$ to $50 \%$. Probability of not having catastrophic impact in both periods is increasing from 60.0 per cent to 98.3 percent as increased in threshold $15 \%$ to 50\%. Catastrophic to catastrophic incidences in Terai ecological belt are higher than in hills and Mountain. Similarly, Disadvantaged non Dalit Terai caste have higher incidence than other caste groups. Synthetic panel gives the indicative trends; incidences may not be directly comparable with incidences estimated from cross-sectional data.
\end{abstract}

Key words: movement of catastrophic payment, medicine cost, synthetic panel, Nepal

\section{INTRODUCTION}

The capacity to monitor and track meaningful change in out-of-pocket health spending and catastrophic payments received special attention since the advent of Universal Health Coverage (UHC) (Boerma et al., 2014). Several methods have been developed to monitor the country level progress towards achievement of UHC, impact of various policies and status of catastrophic health expenditure at national level. In this growing 
literature, the measurement of catastrophic health care payments appears to serve three main objectives: to identify changes in levels of well-being; to assess the extent of poverty / low levels of living at the household level; and to assess the performance of existing health insurance schemes. Naga and Lamiraud (2011) developed a fairly detailed conceptual framework using economic theory which facilitates a clear understanding of existing concepts and methods, and possible limitations. In the empirical front, Van Doorslaer et al. (2007), Van Doorslaer et al. (2005) and Adhikari, Maskay, and Sharma (2009) developed country level evidences about the incidence of catastrophic expenditure and impoverishment impact in developing countries using national level cross-sectional surveys. Wagstaff et al. (2006) used panel data to provide economic consequences of health shocks and health care expenditure.

The interest in the measurement of catastrophic health payments stems from the fact that in the absence of health insurance, high expenditures on health care can severely disrupt household living standards Berki (1986). Ideally, this change in welfare would be assessed with longitudinal data through examination of how health shocks disrupt consumption paths (Gertler \& Gruber, 1997; Wagstaff, 2007). In the absence of longitudinal data, OOP health payments in excess of a threshold budget share have been used as a proxy for severe disruptions to household living standards. Regarding this point, Van Doorslaer et al. (2007) focus on payments that are catastrophic in the sense of severely disrupting household living standards, and approximate such payments by those absorbing a large fraction of household resources. Thus it may be argued that a catastrophic situation may be used to capture a change in household welfare. However, our problem, formulated in general terms therefore is: can the estimate of budget share from cross-section surveys be informative about the direction of a change in household welfare? In this connection, Naga and Lamiraud (2011) suggested that the scope for identifying households who experience a severe decline in their levels of living using a budget share is limited, unless the data analyst is sure that the household has experienced an income drop. Such information about changes in income is however not always available in cross-section type household surveys. The main problem is that it is hoped to identify a change in a variable (household welfare) by means of another variable (a budget share) measured in levels. Therefore, to effectively monitor and track the achievements in UHC, we want to track the households escape catastrophic health expenditure as well as those that remain in or fall back into the catastrophic health expenditure. As Naga and Lamiraud (2011) also proposed to address this limitation by using longitudinal data especially at the household or individual level. However, for most developing countries, cross-sectional data are far more common than panel data. This can be for a variety of reasons. Panel data collection can be very costly, for example, and can also pose a variety of logistical and capacity-related challenges. For whatever reason, the scarcity of panel data 
has limited the analysis of welfare impact of catastrophic health expenditure, if not impossible, in most developing country settings.

To overcome the non-availability of panel data, there have been a number of studies that develop pseudo-panels (or synthetic panels) out of multiple rounds of cross-sectional data. Following the seminal contributions of Deaton (1985) synthetic panels based on age cohorts have been widely used to investigate income and consumption over time (Banks, Blundell, \& Brugiavini, 2001; Deaton \& Paxson, 1993). Perhaps because of their emphasis on cohorts rather than the household or individual, pseudo panel methods have not been widely applied to the analysis of catastrophic health impacts. Against this background, a recent paper by Dang and Lanjouw (2013) proposes both parametric approaches to construct synthetic panels at the household level from two rounds of cross sections with rather parsimonious assumptions. These synthetic panels can then be used to predict point estimates of welfare impact of catastrophic health expenditures.

In the next section, we have described methodology adopted to create a synthetic panel data, modifications in the proposed method that suit the nature of heath expenditure data and detail estimation methodology.

\section{ESTIMATION METHODS AND DATA}

Recently, Dang and Lanjouw (2013) developed a methodology to create a synthetic panel to study the poverty dynamics at household level that requires a minimum of two year cross-section survey rounds. The authors demonstrated that the methodology provides a better performance than the true panel data in terms of asymptotic properties and robustness of estimates provided that certain assumptions are fulfilled. We have attempted to study the mobility of catastrophic expenditure at the household level over the period of time. In the other words, we are interested to calculate percentage of households that faced catastrophic health expenditure in first period but didn't face catastrophic health expenditure in second period. Catastrophic payment is defined as OOP payments as a share of total household resources in excess of some threshold. Household resources are measured by the value of household consumption. Household non-food consumption is considered a better measure of household resources as compared to income or expenditures in developing countries. This is especially relevant for home grown production, which can be significant especially in rural areas. A household is said to have incurred catastrophic payments if $\mathrm{T} / \mathrm{x}>\mathrm{z}$, where $\mathrm{T}$ is OOP health payments, $\mathrm{x}$ is household consumption net of the value of food consumption and $z$ is some thresholds. The latter is arbitrary and results are presented for a variety of values for $z(15 \%, 20 \%, 25 \%, 30 \%, 35 \%$ and $40 \%)$. 
Our purpose is to study the dynamics of catastrophic health expenditure between two periods as developed by Dang and Lanjouw (2013) with some contextual modifications. Following equation shows the probability that a household is catastrophic in the first period and not catastrophic in the second period.

$$
P\left(y_{i 1}<z \text { and } y_{i 2}>z\right)=\phi\left(-\frac{z-\hat{y}_{i 1}}{\sigma_{\varepsilon^{1}}}, \frac{z-\hat{y}_{i 2}}{\sigma_{\varepsilon^{2}}},-P\right)
$$

Where, $y_{i 1}$ and $y_{i 2}$ is the OOP share of total non-food consumption in the first (2003) and second period (2011) respectively. Z represents thresholds for catastrophic health care expenditure. $\sigma_{\varepsilon 1}$ and $\sigma_{\varepsilon 2}$ are standard deviations of residuals from the two part model for two periods. $P$ indicates correlation coefficient between OOP share between two periods; $\phi$ is bivariate normal probability function. Similarly, $\hat{y}_{i 1}$ and $\hat{y}_{i 2}$ are the projection of OOP share of total non-food consumption on household time invariant characteristics between the periods. Dang and Lanjouw (2013) used linear projection of per-capita household consumption to estimate poverty dynamics. However, nature of data for consumption and health expenditure are different. OOP share has many zeros and it is a proportion indicating a need of appropriate model that suites the nature of the data. The standard practice of using linear models to examine how a set of explanatory variables influence a given proportional or fractional response variable is not appropriate in general, since it does not guarantee that the predicted values of the dependent variable are restricted to the unit interval. We used two-part fractional response model (Ramalho, Ramalho, \& Murteira, 2011) to predict the OOP share in this study. These projections are represented by the following equations.

$$
\begin{aligned}
& \hat{y}_{1}=M\left(x_{k 1} \hat{\beta}_{12 p}\right) \times F\left(x_{k 1} \hat{\beta}_{11 p}\right) \\
& \hat{y}^{2}=M\left(x_{k 2} \hat{\beta}_{22 p}\right) \times F\left(x_{k 2} \hat{\beta}_{21 p}\right)
\end{aligned}
$$

Here, $M$ and $F$ represents two link functions. In these models, $M$ indicates cauchit link function while $F$ represents logit link function. Two different sets of coefficients are estimated; $\beta_{1 p}$ represents coefficients for the model estimating whether $\mathrm{HH}$ incurs health expenditure which is a binary variable, and $\beta_{2 p}$ represents HHs having non-zero value of OOP share.

In the equation (1), $P$ is one of the important parameters that derives dynamics between two periods, and it is generally correlation between OOP share in two periods. Dang and Lanjouw (2013) also provided methodology to estimate $P$ using linear dynamic models using age cohort based pseudo panels. However, we assume that illness is a fairly a random event and so is out-of-pocket expenditure. This hypothesis was confirmed by the fact that age cohort dummy variables are not correlated with OOP in 
both survey rounds. So, correlation between OOP share in two periods is derived by correlation between total household non-food consumption. We therefore assume total household non-food consumption follows a simple linear dynamic data-generating process given by

$$
y_{i 2}=\alpha+\delta^{\prime} y_{i 1}+\tau_{i 1}
$$

Where, $\tau_{\mathrm{i} 1}$ is random error term. Also assume that the sample size of each household survey round is large enough (or $N \rightarrow \infty$ ), the number of age cohorts (C) constructed from the survey data is fixed, and the age cohort dummy variables satisfy the relevance and erogeneity criteria for instrumental variables for $y_{i 1}$ in above equation. The simple correlation coefficient $P_{y 1, y 2}$ can then be approximated with the synthetic panel cohort level simple correlation coefficient $P_{y 1, y y^{\prime}}$ where $c$ indexes the age cohorts constructed from the household survey data (Verbeek, 2008). We considered age cohort of 25 to 55 years in 2003 to construct the age cohorts in urban and rural areas. After appropriately identifying the equation, $\mathrm{P}_{\mathrm{y} 1, \mathrm{y} 2}$ can be calculated as follows.

$$
P_{y 1, y 2}=\sqrt{\left(\frac{\operatorname{var}\left(y_{i 1}\right)}{\operatorname{var}\left(y_{i 2}\right)}\right) * \delta}
$$

After calculating $\mathrm{P}_{\mathrm{y} 1, \mathrm{y} 2^{2}}$ P can be calculated as follows.

$$
P=\frac{P_{y 1, y 2}-\sqrt{R_{1}^{2} \times R_{2}^{2}}}{\sqrt{1-R_{1}^{2}} \times \sqrt{1-R^{2}}}
$$

With these parameters in hand, according to (Dang \& Lanjouw, 2013) the mobility of into and out of catastrophic payment in context of synthetic panels can be defined as follows:

a) Probability of being catastrophic in first period remaining catastrophic in second period.

$$
P\left(y_{i 1}>z \text { and } y_{i 2}>z\right)=\phi\left(-\frac{z-\hat{y}_{1}}{\sigma_{\varepsilon_{1}}},-\frac{z-\hat{y}^{2}}{\sigma_{\varepsilon^{2}}}, P\right)
$$


b) Probability of being catastrophic in first period becoming non-catastrophic in second period.

$$
P\left(y_{i 1}>z \text { and } y_{i 2}<z\right)=\phi\left(-\frac{z-\hat{y}_{1}}{\sigma_{\varepsilon^{1}}},-\frac{z-\hat{y}^{2}}{\sigma_{\varepsilon^{2}}}, P\right)
$$

c) Probability of being non-catastrophic in first period becoming catastrophic in second period.

$$
P\left(y_{i 1}<z \text { and } y_{i 2}>z\right)=\phi\left(\frac{z-\hat{y}_{1}}{\sigma_{\varepsilon 1}},-\frac{z-\hat{y}^{2}}{\sigma_{\varepsilon^{2}}}, P\right)
$$

d) Probability of being non-catastrophic in first period becoming non-catastrophic in second period.

$$
P\left(y_{i 1}<z \text { and } y^{i 2}<z\right)=\phi\left(\frac{z-\hat{y}^{1}}{\sigma_{\varepsilon^{1}}}, \frac{z-\hat{y}^{2}}{\sigma_{\varepsilon^{2}}}, P\right)
$$

These joint probabilities have been calculated for out-of-pocket expenditure and expenditure on medicine. The standard errors of these point estimates were calculated using bootstrap method at 1000 replications in R. All the equations were coded in R software for statistical computing. Joint probabilities for the Equations 7 to 10 were calculated using pbivnorm package developed by Kenkel (2012) in R.

\section{Sources of Data}

We analysed household survey data from Nepal Living Standard Survey (NLSS) which were undertaken by Central Bureau of Statistics (CBS), Government of Nepal using Living Standard Measurement Survey developed and used in a series of developing countries to monitor the poverty alleviation goals by The World Bank; two rounds of data were used in the analysis i.e. 2003/04 and 2010/11. The total numbers of households were 2769 in 2003/04 and 4166 in 2010/11. The surveys provide detailed information on household consumption, health care expenditure for chronic non-communicable and communicable diseases, demographics, as well as schooling, health employment, migration, and housing. Information about health expenditure was asked for last one month during the survey. Summary data coverage is presented in Table 1. 
Table 1: Summary of Data Coverage

Description

\section{Nepal Living Standard Surveys}

NLSS II

326 (3912 households)

NLSS III

Number of primary

sampling units cross-

sectional data

Survey methods

National representative survey

Coverage of surveys

\section{Living standard \\ measurement survey}

Covered all development

regions, rural/urban and ecological belts

Household information, income, consumption, saving, education, health, remittance, government facilities among others
499 (5988 households)

Living standard

measurement survey

Covered all development regions, rural/urban and ecological belts

Household information, income, consumption, saving, education, health, remittance, government facilities among others

Food expenses and home production (the value of goods consumed from home production, in addition to expenditures incurred through market purchase); Nonfood expenditure and inventory of durable goods (non-food consumption, "use values" of consumer durables rather than the actual expenditures on such items, housing expenses, in the form of rent (actual for tenants and imputed for owneroccupiers) and payments for utilities (e.g. electricity, water); Health expenditure (includes cost of consultation, cost of travel, cost of medicine and others) for illness and injury last 30 days and other household information were extracted from sections 5, 6 and 8 of the questionnaires of NLSS 1995/96, NLSS 2003/04 and NLSS 2010/11. Raw data are in STATA and SPSS. All data were managed, cleaned and verified with summary results published by CBS. Then data ware analysed.

Source: "NLSS I" "NLSS II" \& "NLSS III" is Nepal Living Standard Survey Conducted by Government of Nepal, Central Bureau of Statistics during 1995-96, 2003-04 and 2011-12 respectively. 
Variables in the Study and Operational Definition

The study included the following variables

i. Expenditure on medicine: This includes monthly expenditure on health services needed to manage the list of infectious diseases outlined in NLSS-III report.

ii. Out-of-pocket (OOP) payments for health care: Out-of-pocket payment includes cost to the patient for consultation/diagnosis and medicine. It was also calculated as monthly expenditure.

iii. OOP share: OOP share is the ratio of Out-of-Pocket expenditure to total monthly consumption of $\mathrm{HH}$. It is expressed in percentage.

iv. Catastrophic Payment: O'Donnell and Wagstaff (2008) defined any payment for health care as catastrophic if it exceeds certain threshold of percentage. It is generally defined $10 \%$ as threshold for OOP share for catastrophic payments.

v. Total Consumption: This is the total consumption of $\mathrm{HH}$ as measured by Living Standard Measurement Technique (O'Donnell and Wagstaff, 2008)

vi. Household head's time invariant characteristics such as place of residence, education, caste and sex of $\mathrm{HH}$.

vii. Other $\mathrm{HH}$ characteristics such as consumption quintile, place of residence, ecological and geographical region.

\section{RESULTS}

\section{Description of Analysis}

Table 1 shows descriptive statistics for the variables used in the analysis. Both Medical expenditure and OOP expenditure are increased by more than two folds. In the survey year 2010/11, the highest expenditure on medicine is in fifth quantile, however, in the survey year 2003/04, tenth consumption quantile has the highest expenditure on medicine. Same trend holds for OOP expenditure. Per capita consumption and total consumption also increased by slightly more than two folds between the two survey years. 


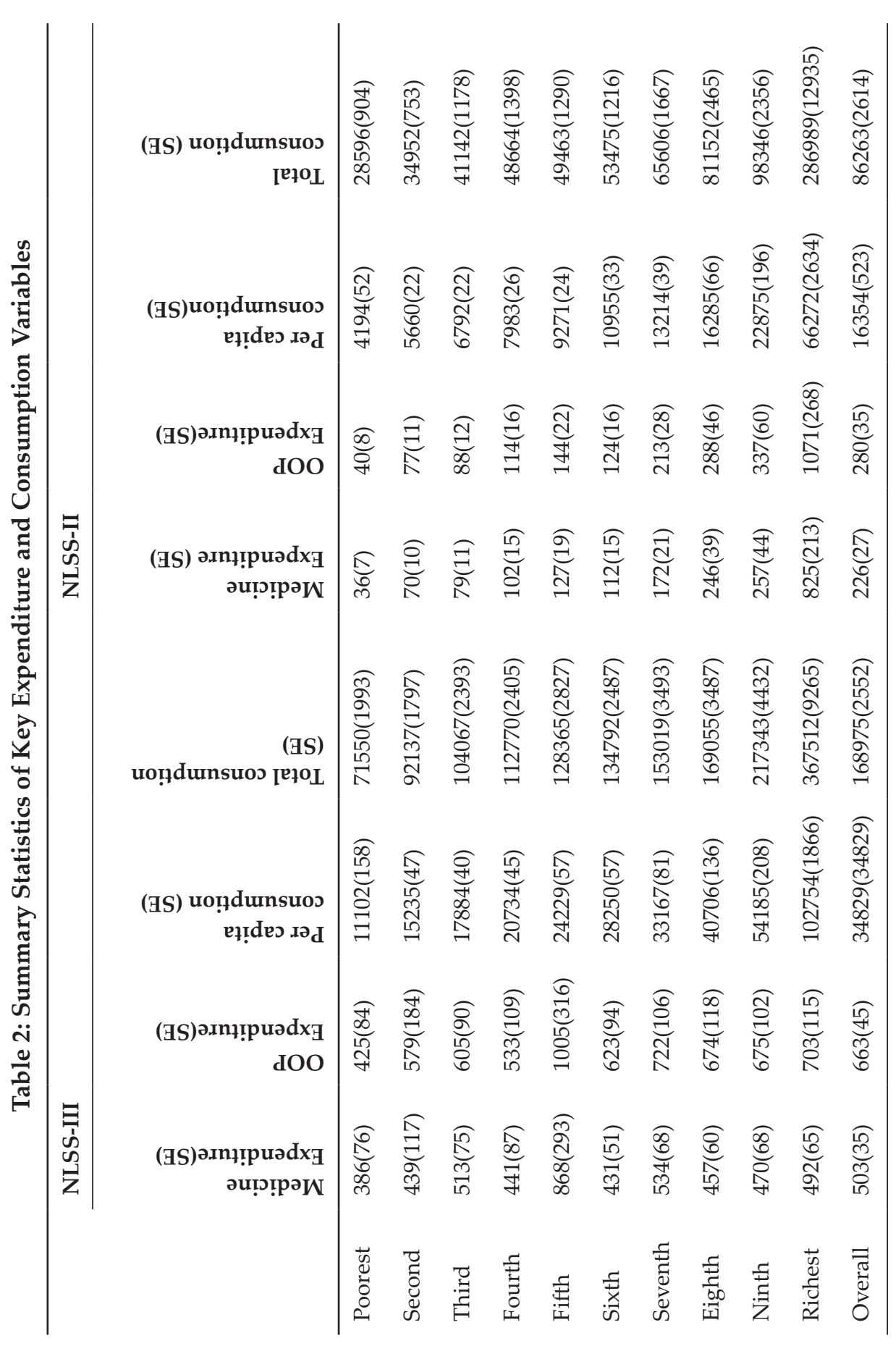




\section{Point Estimate of Welfare Analysis}

\section{a. Estimation of $P$}

Consistent with the literature of pseudo-panel data, we restricted households' age range to 25-55 for the first survey round (2003/04) and adjusted this appropriately in next survey round i.e. we considered age range of 32-62 in survey year 2010/2011). While this age range can be extended to include older people, it has been ill-advised to include those who are younger, at least since most household heads tend to be older than 25. After obtaining the point estimate using equation 4 , we calculated the value of $P_{y 1, y 2}$ using equation 5. Similarly, using equation 6, we finally calculated the value of $P$ which was found to be 0.92 . The two part model according to the equation 2 and 3 were fitted separately for share of OOP and medical expenditure as a percentage of non-food consumption. The results are available in Annex-I. With the help of fitted values from two part model together with the value of $P$, the point estimate of mobility of households for catastrophic health expenditure between two survey periods were calculated using equations 7 to 10 .

Table 3: Age Cohort Based Simple Linear Dynamic Model

\begin{tabular}{lllll}
\hline & \multicolumn{4}{c}{ Total non-food consumption } \\
2010/11 \\
Covariates & Estimate & Std. Err. & t-value & p-value \\
\hline Intercept & 2806 & 683.9 & 4.103 & $<0.0001$ \\
Total Non-Food Consumption 2003 & 1.063 & 0.08201 & 12.958 & $<0.0001$ \\
\hline
\end{tabular}

\section{b. Estimation of mobility values for catastrophic health expenditure}

Table 3 shows the mobility of households between the status of catastrophic health expenditure and non-catastrophic health expenditure between two survey periods. The threshold for catastrophic health expenditure for non-food expenditure is set between $15 \%$ to $50 \%$. Against this threshold, the mobility of the population for catastrophic payment between two periods have been measured for Out-of-Pocket payments and expenses on medicine. From the table 4, it can be observed that at $15 \%$ threshold, 24 percentage of households suffered from catastrophic health expenditure in both periods. This percentage gradually decreases as the threshold value increases. At threshold value of $40 \%$, only one percentage of households suffer from catastrophic health expenditure in both periods. Movement of household from catastrophic payments to not suffering from catastrophic payments is comparatively very low i.e. 3.1 percent at $15 \%$ threshold, and as the threshold increased to $45 \%$, it diminishes nearly to zero. Similarly, 16.4 percent of households suffer from catastrophic health expenditure in 2010/11 who didn't suffer catastrophic health expenses in the year 2003/04. As can be see, flow from non-catastrophic to catastrophic is higher than 
catastrophic to non-catastrophic which indicates that one average, between twosurvey periods, increasing number of new households are suffering from catastrophic health expense in later year. A Majority of households remained in the state of noncatastrophic health expenditure in both periods.

Table 4: Households' Mobility for Catastrophic Payments between Survey Year 2003/04 and 2010/11

\begin{tabular}{|c|c|c|c|c|c|c|c|c|}
\hline \multirow{2}{*}{ Threshold } & \multicolumn{4}{|c|}{ Out of Pocket Expenses } & \multicolumn{4}{|c|}{ Medical Expenses } \\
\hline & $\mathrm{C} 2 \mathrm{C}$ & $\mathrm{C} 2 \mathrm{NC}$ & $\mathrm{NC} 2 \mathrm{C}$ & NC2NC & $\mathrm{C} 2 \mathrm{C}$ & $\mathrm{C} 2 \mathrm{NC}$ & $\mathrm{NC} 2 \mathrm{C}$ & $\mathrm{NC} 2 \mathrm{NC}$ \\
\hline $15 \%$ & $24.3(1.2)$ & $3.1(1)$ & $16.4(1.3)$ & $56.2(1.1)$ & $20.1(1.1)$ & $2.6(0.9)$ & 17.2(1.3) & $60(1.1)$ \\
\hline $20 \%$ & $15.3(1)$ & $1.9(0.8)$ & $16.6(1.2)$ & $66.2(1)$ & $11.3(0.9)$ & $1.5(0.6)$ & $16.8(1.2)$ & $70.4(1)$ \\
\hline $25 \%$ & $8.8(0.8)$ & $1.1(0.5)$ & $15.3(1.1)$ & $74.9(1)$ & $5.6(0.6)$ & $0.7(0.4)$ & $14.5(1.1)$ & 79.1(1) \\
\hline $30 \%$ & $4.6(0.6)$ & $0.6(0.3)$ & $12.8(1)$ & $82(0.9)$ & $2.5(0.4)$ & $0.3(0.2)$ & $11.2(0.9)$ & $85.9(0.9)$ \\
\hline $35 \%$ & $2.2(0.3)$ & $0.3(0.2)$ & $9.9(0.8)$ & $87.7(0.8)$ & $1(0.2)$ & $0.1(0.1)$ & $7.9(0.8)$ & $91(0.8)$ \\
\hline $40 \%$ & $0.9(0.2)$ & $0.1(0.1)$ & $7.1(0.7)$ & $91.9(0.7)$ & $0.3(0.1)$ & $0.1(0)$ & $5.1(0.6)$ & $94.5(0.6)$ \\
\hline $45 \%$ & $0.4(0.1)$ & $0(0)$ & $4.7(0.5)$ & $94.9(0.5)$ & $0.1(0)$ & $0(0)$ & $3(0.4)$ & $96.8(0.4)$ \\
\hline $50 \%$ & $0.1(0)$ & $0(0)$ & $2.9(0.4)$ & $96.9(0.4)$ & $0(0)$ & $0(0)$ & $1.7(0.3)$ & $98.3(0.3)$ \\
\hline
\end{tabular}

Note: $\mathrm{C} 2 \mathrm{C}=$ Catastrophic to Catastrophic; $\mathrm{C} 2 \mathrm{NC}=\mathrm{C}$ atastrophic to non-catastrophic; $\mathrm{NC} 2 \mathrm{C}=\mathrm{Non}$ catastrophic to Catastrophic; NC2NC=Non-catastrophic to Non-Catastrophic

\section{Stratified Analysis of Mobility}

This section explains the findings of catastrophic payment mobility between two periods across various household and geographic characteristics. Table 4 shows the stratification across ecological region. Tarai region shows the highest percentage of households remaining in the catastrophic health expenditure in two periods. Movement from catastrophic to non-catastrophic health expenditure is the highest in hills. Similarly, relatively fewer percentages of households (11.7\%) in hills transit from non-catastrophic to catastrophic status between two survey periods when compared with figures of tarai and mountain region. The table therefore indicates that there are relatively the highest percentages of households move from catastrophic to catastrophic as well as non-catastrophic to catastrophic in tarai region when compared with other ecological zones. 
Table 5: Stratification of Mobility across Ecological Belt

\begin{tabular}{|c|c|c|c|c|c|c|c|c|}
\hline \multirow[b]{3}{*}{ Threshold } & \multicolumn{4}{|c|}{ Out of Pocket Expenses } & \multicolumn{4}{|c|}{ Medical Expenses } \\
\hline & $\mathrm{C} 2 \mathrm{C}$ & $\mathrm{C} 2 \mathrm{NC}$ & $\mathrm{NC} 2 \mathrm{C}$ & NC2NC & $\mathrm{C} 2 \mathrm{C}$ & $\mathrm{C} 2 \mathrm{NC}$ & $\mathrm{NC} 2 \mathrm{C}$ & NC2NC \\
\hline & \multicolumn{8}{|l|}{ Tarai } \\
\hline $15 \%$ & $25.8(1.2)$ & $1.9(1)$ & $22.2(1.3)$ & $50.2(1.1)$ & 21.4(1.1) & $1.6(0.9)$ & $23.5(1.3)$ & $53.5(1.1)$ \\
\hline $20 \%$ & $16.3(1)$ & $1.1(0.8)$ & $22.5(1.2)$ & $60.1(1.1)$ & $12(0.9)$ & $0.9(0.6)$ & $22.9(1.2)$ & $64.2(1.1)$ \\
\hline $25 \%$ & $9.3(0.8)$ & $0.6(0.5)$ & $20.7(1.1)$ & $69.3(1)$ & $6(0.6)$ & $0.4(0.4)$ & $19.9(1.1)$ & $73.6(1)$ \\
\hline $30 \%$ & $4.9(0.6)$ & $0.3(0.3)$ & $17.5(1)$ & $77.3(0.9)$ & $2.7(0.4)$ & $0.2(0.2)$ & $15.7(0.9)$ & $81.5(0.9)$ \\
\hline $35 \%$ & $2.3(0.3)$ & $0.1(0.2)$ & $13.7(0.8)$ & $83.8(0.8)$ & $1(0.2)$ & $0.1(0.1)$ & $11.3(0.8)$ & $87.6(0.8)$ \\
\hline $40 \%$ & $1(0.2)$ & $0.1(0.1)$ & $9.9(0.7)$ & $89(0.7)$ & $0.4(0.1)$ & $0(0)$ & $7.4(0.6)$ & $92.2(0.6)$ \\
\hline $45 \%$ & $0.4(0.1)$ & $0(0)$ & $6.8(0.5)$ & $92.8(0.5)$ & $0.1(0)$ & $0(0)$ & $4.6(0.4)$ & $95.3(0.4)$ \\
\hline \multirow[t]{2}{*}{$50 \%$} & $0.1(0)$ & $0(0)$ & $4.3(0.4)$ & $95.5(0.4)$ & $0(0)$ & $0(0)$ & $2.6(0.3)$ & $97.3(0.3)$ \\
\hline & \multicolumn{8}{|l|}{ Hills } \\
\hline $15 \%$ & 23.1(1.2) & $4.2(1)$ & $11.7(1.3)$ & $61(1.1)$ & $19.2(1.1)$ & $3.6(0.9)$ & $12.3(1.3)$ & $65(1.1)$ \\
\hline $20 \%$ & $14.5(1)$ & $2.6(0.8)$ & $11.9(1.2)$ & $70.9(1)$ & $10.8(0.9)$ & $2(0.6)$ & $12(1.2)$ & $75.2(1)$ \\
\hline $25 \%$ & $8.3(0.8)$ & $1.5(0.5)$ & $10.9(1.1)$ & 79.3(1) & $5.4(0.6)$ & $1(0.4)$ & $10.3(1.1)$ & $83.3(1)$ \\
\hline $30 \%$ & $4.4(0.6)$ & $0.8(0.3)$ & $9(1)$ & $85.8(0.9)$ & $2.4(0.4)$ & $0.5(0.2)$ & $7.8(0.9)$ & $89.4(0.9)$ \\
\hline $35 \%$ & $2.1(0.3)$ & $0.4(0.2)$ & $6.8(0.8)$ & $90.7(0.8)$ & $0.9(0.2)$ & $0.2(0.1)$ & $5.3(0.8)$ & $93.6(0.8)$ \\
\hline $40 \%$ & $0.9(0.2)$ & $0.2(0.1)$ & $4.8(0.7)$ & $94.2(0.7)$ & $0.3(0.1)$ & $0.1(0)$ & $3.3(0.6)$ & $96.3(0.6)$ \\
\hline $45 \%$ & $0.3(0.1)$ & $0.1(0)$ & $3.1(0.5)$ & $96.5(0.5)$ & $0.1(0)$ & $0(0)$ & $1.9(0.4)$ & $98(0.4)$ \\
\hline \multirow[t]{2}{*}{$50 \%$} & $0.1(0)$ & $0(0)$ & $1.8(0.4)$ & $98(0.4)$ & $0(0)$ & $0(0)$ & $1(0.3)$ & $99(0.3)$ \\
\hline & \multicolumn{8}{|c|}{ Mountain } \\
\hline $15 \%$ & $24.1(1.3)$ & $2.5(1.1)$ & $15.7(1.4)$ & $57.8(1.2)$ & $19.7(1.2)$ & $2.2(1)$ & $15.6(1.4)$ & $62.4(1.2)$ \\
\hline $20 \%$ & $15(1.1)$ & $1.5(0.8)$ & $15.9(1.3)$ & $67.6(1.1)$ & $11(1)$ & $1.2(0.7)$ & $15.1(1.3)$ & $72.7(1.2)$ \\
\hline $25 \%$ & $8.5(0.8)$ & $0.8(0.6)$ & $14.6(1.2)$ & 76.1(1.1) & $5.4(0.7)$ & $0.6(0.4)$ & $12.9(1.2)$ & 81.1(1.1) \\
\hline $30 \%$ & $4.4(0.6)$ & $0.4(0.4)$ & 12.1(1) & 83.1(1) & $2.3(0.4)$ & $0.3(0.2)$ & $9.8(1)$ & $87.6(1)$ \\
\hline $35 \%$ & $2(0.3)$ & $0.2(0.2)$ & $9.2(0.9)$ & $88.6(0.9)$ & $0.9(0.2)$ & $0.1(0.1)$ & $6.7(0.8)$ & $92.3(0.8)$ \\
\hline $40 \%$ & $0.9(0.2)$ & $0.1(0.1)$ & $6.4(0.7)$ & $92.6(0.7)$ & $0.3(0.1)$ & $0.1(0.1)$ & $4.2(0.6)$ & $95.5(0.6)$ \\
\hline $45 \%$ & $0.3(0.1)$ & $0(0.1)$ & $4.2(0.6)$ & $95.4(0.6)$ & $0.1(0)$ & $0(0)$ & $2.4(0.4)$ & $97.5(0.5)$ \\
\hline $50 \%$ & $0.1(0)$ & $0(0)$ & $2.5(0.4)$ & $97.3(0.4)$ & $0(0)$ & $0(0)$ & $1.3(0.3)$ & $98.7(0.3)$ \\
\hline
\end{tabular}

Note: $\mathrm{C} 2 \mathrm{C}=$ Catastrophic to Catastrophic; $\mathrm{C} 2 \mathrm{NC}=$ Catastrophic to non-catastrophic; $\mathrm{NC} 2 \mathrm{C}=\mathrm{Non}$ catastrophic to Catastrophic; NC2NC=Non-catastrophic to Non-Catastrophic 
Table 6: Stratification of Mobility across Various Ethnic Group

\begin{tabular}{|c|c|c|c|c|c|c|c|c|}
\hline & \multicolumn{4}{|c|}{ Out of Pocket Expenses } & \multicolumn{4}{|c|}{ Medical Expenses } \\
\hline & $\mathrm{C} 2 \mathrm{C}$ & $\mathrm{C} 2 \mathrm{NC}$ & $\mathrm{NC} 2 \mathrm{C}$ & NC2NC & $\mathrm{C} 2 \mathrm{C}$ & $\mathrm{C} 2 \mathrm{NC}$ & $\mathrm{NC} 2 \mathrm{C}$ & NC2NC \\
\hline Threshold & \multicolumn{8}{|l|}{ Dalits } \\
\hline $15 \%$ & $25.6(1.2)$ & $2(1)$ & 20.1(1.4) & $52.4(1.2)$ & $21.3(1.2)$ & $1.7(0.9)$ & 21.4(1.4) & $55.7(1.2)$ \\
\hline $20 \%$ & 16.1(1.1) & $1.2(0.8)$ & $20.4(1.3)$ & $62.3(1.1)$ & $12(0.9)$ & $1(0.6)$ & $20.8(1.3)$ & 66.2(1.1) \\
\hline $25 \%$ & $9.2(0.8)$ & $0.7(0.5)$ & $18.8(1.2)$ & $71.3(1)$ & $6(0.7)$ & $0.5(0.4)$ & 18.1(1.2) & $75.5(1.1)$ \\
\hline $30 \%$ & $4.8(0.6)$ & $0.4(0.3)$ & $15.8(1)$ & & $2.6(0.4)$ & $0.2(0.2)$ & $14.1(1)$ & \\
\hline $35 \%$ & $2.3(0.3)$ & $0.2(0.2)$ & $12.3(0.9)$ & $85.3(0.8)$ & $1(0.2)$ & $0.1(0.1)$ & $10(0.8)$ & $88.9(0.8)$ \\
\hline $40 \%$ & $1(0.2)$ & $0.1(0.1)$ & $8.8(0.7)$ & $90.1(0.7)$ & $0.4(0.1)$ & $0(0)$ & $6.5(0.6)$ & $93.1(0.6)$ \\
\hline $45 \%$ & $0.4(0.1)$ & $0(0)$ & $5.9(0.5)$ & $93.7(0.5)$ & $0.1(0)$ & $0(0)$ & $3.9(0.4)$ & $95.9(0.4)$ \\
\hline \multirow[t]{2}{*}{$50 \%$} & $0.1(0)$ & $0(0)$ & $3.7(0.4)$ & $96.1(0.4)$ & $0(0)$ & $0(0)$ & $2.2(0.3)$ & $97.7(0.3)$ \\
\hline & \multicolumn{8}{|c|}{ Disadvantaged Janajatis } \\
\hline $15 \%$ & $24.9(1.2)$ & $2(1)$ & 19.9(1.3) & $53.1(1.1)$ & $20.6(1.1)$ & $1.8(0.9)$ & $21(1.3)$ & $56.7(1.1)$ \\
\hline $20 \%$ & $15.6(1)$ & $1.2(0.8)$ & 20.1(1.2) & $63(1.1)$ & $11.5(0.9)$ & $1(0.6)$ & $20.3(1.2)$ & 67.2(1.1) \\
\hline $25 \%$ & $8.9(0.8)$ & $0.7(0.5)$ & 18.5(1.1) & $72(1)$ & $5.7(0.6)$ & $0.5(0.4)$ & 17.5(1.1) & $76.3(1)$ \\
\hline $30 \%$ & $4.6(0.6)$ & $0.3(0.3)$ & $15.5(1)$ & $79.6(0.9)$ & $2.5(0.4)$ & $0.2(0.2)$ & $13.6(0.9)$ & $83.7(0.9)$ \\
\hline $35 \%$ & $2.2(0.3)$ & $0.2(0.2)$ & $12(0.8)$ & $85.7(0.8)$ & $1(0.2)$ & $0.1(0.1)$ & $9.6(0.8)$ & $89.3(0.8)$ \\
\hline $40 \%$ & $0.9(0.2)$ & $0.1(0.1)$ & $8.6(0.7)$ & $90.4(0.7)$ & $0.3(0.1)$ & $0(0)$ & $6.2(0.6)$ & $93.4(0.6)$ \\
\hline $45 \%$ & $0.4(0.1)$ & $0(0)$ & $5.7(0.5)$ & $93.9(0.5)$ & $0.1(0)$ & $0(0)$ & $3.8(0.4)$ & $96.1(0.4)$ \\
\hline \multirow{2}{*}{\multicolumn{9}{|c|}{$50 \%$}} \\
\hline & & & & & & & & \\
\hline $15 \%$ & $26.9(1.2)$ & $1.7(1)$ & $24.1(1.4)$ & $47.4(1.2)$ & $22.3(1.2)$ & $1.5(0.9)$ & $25.4(1.4)$ & $50.8(1.2)$ \\
\hline $20 \%$ & 17.1(1.1) & $1(0.8)$ & & & $12.7(0.9)$ & & & $61.6(1.1)$ \\
\hline $25 \%$ & $9.9(0.8)$ & $0.6(0.6)$ & $22.8(1.2)$ & $66.8(1)$ & $6.4(0.7)$ & $0.4(0.4)$ & $21.8(1.2)$ & $71.3(1.1)$ \\
\hline $30 \%$ & $5.2(0.6)$ & $0.3(0.3)$ & $19.4(1)$ & 75.1 & $2.9(0.4)$ & $0.2(0.2)$ & $17.3(1)$ & $79.6(1)$ \\
\hline $35 \%$ & $2.5(0.3)$ & $0.1(0$. & 15.3 & & $1.1(0.2)$ & 0.1( & & \\
\hline $40 \%$ & $1.1(0.2)$ & $0.1(0.1)$ & $11.2(0.7)$ & $87.7(0.7)$ & $0.4(0.1)$ & $0(0)$ & $8.4(0.6)$ & $91.2(0.6)$ \\
\hline $45 \%$ & $0.4(0.1)$ & $0(0)$ & $7.7(0.5)$ & $91.9(0.5)$ & $0.1(0)$ & $0(0)$ & $5.2(0.4)$ & $94.7(0.4)$ \\
\hline $50 \%$ & $0.2(0)$ & $0(0)$ & $5(0.4)$ & $94.9(0.4)$ & $0(0)$ & $0(0)$ & $3(0.3)$ & $96.9(0.3)$ \\
\hline & \multicolumn{8}{|c|}{ Religious Minorities } \\
\hline $15 \%$ & $26(1.3)$ & $1.6(1.1)$ & $23.6(1.6)$ & & $21.7(1.2)$ & 1.5( & & $51.9(1.4)$ \\
\hline $20 \%$ & $16.4(1.1)$ & $1(0.9)$ & & & & & & $5(1.3)$ \\
\hline $25 \%$ & $9.4(($ & $0.5(0.6)$ & & & $6.2(0.7)$ & & & 72.1(1.2) \\
\hline $30 \%$ & $5(0.6)$ & $0.2(0.4)$ & $18.8(1.2)$ & $76(1$. & $2.8(0.4)$ & $0.2(0.3)$ & $16.9(1.1)$ & $80.1(1.1)$ \\
\hline $35 \%$ & $2.4(0.4)$ & $0.1(0.2)$ & $14.8(1)$ & $82.7(C$ & $1.1(0.2)$ & $0.1(0.1)$ & $12.3(0.9)$ & $86.5(0.9)$ \\
\hline $40 \%$ & $1(0.2)$ & $0(0.1)$ & 10.8 & & $0.4(0.1)$ & $0(0.1)$ & & $91.3(0.7)$ \\
\hline $45 \%$ & $0.4(0.1)$ & $0(0.1)$ & $7.4(0$ & & $0.1(0)$ & $0(0)$ & 5.2( & $94.7(0.5)$ \\
\hline \multirow[t]{2}{*}{$50 \%$} & $0.1(0)$ & $0(0)$ & $4.8(0.4)$ & $95.1(0.4$ & $0(0)$ & $0(0)$ & $3(0$. & $96.9(0.3)$ \\
\hline & \multicolumn{8}{|c|}{ Relatively advantaged Janajatis } \\
\hline $15 \%$ & $22.4(1.2)$ & $5.2(1)$ & $9.7(1.4)$ & & $18.6(1.2)$ & & $10(1.4)$ & $67(1.2)$ \\
\hline $20 \%$ & 14.1(1.1) & $3.3(0.8)$ & & & & & & 77.2(1.1) \\
\hline $25 \%$ & $8.1(0.8)$ & $1.9(0.6)$ & $9.2(1.2)$ & & $5.3(0.7)$ & 1.2( & & \\
\hline $30 \%$ & $4.3(0.6)$ & $1(0.3)$ & $7.6(1)$ & 87.2 & $2.3(0.4)$ & $0.5(0.2)$ & 6.4( & $90.7(0.9)$ \\
\hline $35 \%$ & $2(0.3)$ & $0.5(0.2)$ & & 91.8 & $0.9(0.2)$ & $0.2(0.1)$ & $4.3(0.8)$ & $94.5(0.8)$ \\
\hline $40 \%$ & $0.9(0.2)$ & $0.2(0.1)$ & $4(0.7)$ & & $0.3(0.1)$ & $0.1(0)$ & & $96.9(0.6)$ \\
\hline $45 \%$ & $0.3(0.1)$ & $0.1(0)$ & & & $0.1(0)$ & $0(0)$ & 1.5 & $98.4(0.4)$ \\
\hline \multirow[t]{2}{*}{$50 \%$} & $0.1(0)$ & $0(0)$ & $1.5(0.4)$ & $98.4(0.4)$ & $0(0)$ & $0(0)$ & $0.8(0.3)$ & $99.2(0.3)$ \\
\hline & \multicolumn{8}{|c|}{ Upper caste groups } \\
\hline $15 \%$ & $23.1(1.2)$ & & $11.6(1.3)$ & 61.1(1.1) & 19.1(1.1) & $3.5(0.9)$ & $12.3(1.3)$ & $65.1(1.1)$ \\
\hline $20 \%$ & $14.5(1)$ & $2.6(0.8)$ & $11.9(1.2)$ & $71(1.1)$ & $10.8(0.9)$ & $1.9(0.6)$ & $12(1.2)$ & $75.3(1.1)$ \\
\hline & $8.3(0.8)$ & $1.5(0$. & $10.9(1.1)$ & & $5.4(0.6)$ & $1(0.4)$ & 10.3( & $83.4(1)$ \\
\hline $30 \%$ & $4.3(0.6)$ & $0.8(0$ & $9(1)$ & & $2.4(0.4)$ & $0.4(0.2)$ & $7.8(0$ & $89.4(0.9)$ \\
\hline $35 \%$ & $2.1(0.3)$ & $0.4(0.2)$ & $6.8(0.8)$ & 90.8( & $0.9(0.2)$ & $0.2(0.1)$ & $5.3(0.8)$ & $93.6(0.8)$ \\
\hline $40 \%$ & $0.9(0.2)$ & $0.2(0.1)$ & $4.7(0.7)$ & 94.2( & $0.3(0.1)$ & $0.1(0)$ & $3.3(0.6)$ & $96.3(0.6)$ \\
\hline $45 \%$ & $0.3(0.1)$ & $0.1(0)$ & $3(0.5)$ & $96.5(0.5)$ & $0.1(0)$ & $0(0)$ & $1.9(0.4)$ & $98(0.4)$ \\
\hline $50 \%$ & $0.1(0)$ & $0(0)$ & $1.8(0.4)$ & $98(0.4)$ & $0(0)$ & $0(0)$ & $1(0.3)$ & $99(0.3)$ \\
\hline
\end{tabular}

Note: $\mathrm{C} 2 \mathrm{C}=$ Catastrophic to Catastrophic; $\mathrm{C} 2 \mathrm{NC}=$ Catastrophic to non-catastrophic; $\mathrm{NC} 2 \mathrm{C}=$ Non-catastrophic to Catastrophic; NC2NC=Non-catastrophic to Non-Catastrophic 
Table 7: Stratification of Mobility across Various Geographic Regions

\begin{tabular}{|c|c|c|c|c|c|c|c|c|}
\hline \multirow[b]{3}{*}{ Threshold } & \multicolumn{4}{|c|}{ Out of Pocket Expenses } & \multicolumn{4}{|c|}{ Medical Expenses } \\
\hline & $\mathrm{C} 2 \mathrm{C}$ & $\mathrm{C} 2 \mathrm{NC}$ & $\mathrm{NC} 2 \mathrm{C}$ & NC2NC & $\mathrm{C} 2 \mathrm{C}$ & $\mathrm{C} 2 \mathrm{NC}$ & $\mathrm{NC} 2 \mathrm{C}$ & NC2NC \\
\hline & \multicolumn{8}{|c|}{ Eastern Region } \\
\hline $15 \%$ & $24.5(1.2)$ & $2.4(1)$ & $18(1.3)$ & 55.1(1.1) & $20.2(1.1)$ & $2(0.9)$ & $18.7(1.3)$ & 59.1(1.1) \\
\hline $20 \%$ & 15.3(1.1) & $1.5(0.8)$ & $18.2(1.3)$ & 65.1(1.1) & $11.3(0.9)$ & $1.1(0.6)$ & 18.1(1.2) & 69.5(1.1) \\
\hline $25 \%$ & $8.7(0.8)$ & $0.8(0.5)$ & $16.6(1.1)$ & 73.8(1) & $5.6(0.6)$ & $0.6(0.4)$ & 15.6(1.1) & 78.3(1) \\
\hline $30 \%$ & $4.5(0.6)$ & $0.4(0.3)$ & 13.9(1) & $81.2(0.9)$ & $2.4(0.4)$ & $0.3(0.2)$ & 12(1) & $85.3(0.9)$ \\
\hline $35 \%$ & $2.1(0.3)$ & $0.2(0.2)$ & $10.7(0.9)$ & $87(0.8)$ & $0.9(0.2)$ & $0.1(0.1)$ & $8.4(0.8)$ & $90.6(0.8)$ \\
\hline $40 \%$ & $0.9(0.2)$ & $0.1(0.1)$ & $7.6(0.7)$ & $91.4(0.7)$ & $0.3(0.1)$ & $0(0)$ & $5.4(0.6)$ & $94.3(0.6)$ \\
\hline $45 \%$ & $0.3(0.1)$ & $0(0)$ & $5(0.5)$ & $94.6(0.5)$ & $0.1(0)$ & $0(0)$ & $3.2(0.4)$ & $96.7(0.4)$ \\
\hline \multirow{2}{*}{$50 \%$} & $0.1(0)$ & $0(0)$ & $3.1(0.4)$ & $96.7(0.4)$ & $0(0)$ & $0(0)$ & $1.8(0.3)$ & $98.2(0.3)$ \\
\hline & \multicolumn{8}{|c|}{ Central Region } \\
\hline $15 \%$ & 23.9(1.2) & $3.9(1)$ & $13.6(1.3)$ & $58.6(1.1)$ & 19.7(1.1) & $3.5(0.9)$ & 13.7(1.3) & 63.1(1.1) \\
\hline $20 \%$ & 15.1(1) & $2.5(0.8)$ & 13.9(1.3) & $68.5(1.1)$ & $11.2(0.9)$ & $2(0$. & 13.4(1.2) & 73.5(1.1) \\
\hline $25 \%$ & $8.7(0.8)$ & $1.4(0.5)$ & $12.8(1.1)$ & 77.1(1) & $5.6(0.6)$ & $1(0$ & $11.6(1.1)$ & $81.8(1)$ \\
\hline $30 \%$ & $4.6(0.6)$ & $0.7(0.3)$ & $10.8(1)$ & $83.9(0.9)$ & $2.5(0.4)$ & 0.4( & $8.9(0.9)$ & $88.1(0.9)$ \\
\hline $35 \%$ & $2.2(0.3)$ & $0.3(0.2)$ & $8.3(0.8)$ & $89.2(0.8)$ & $1(0.2)$ & $0.2(0.1)$ & $6.2(0.8)$ & $92.6(0.8)$ \\
\hline $40 \%$ & $0.9(0.2)$ & $0.1(0.1)$ & $5.9(0.7)$ & $93(0.7)$ & $0.3(0.1)$ & $0.1(0)$ & $3.9(0.6)$ & $95.7(0.6)$ \\
\hline $45 \%$ & $0.4(0.1)$ & $0.1(0)$ & $3.9(0.5)$ & $95.7(0.5)$ & $0.1(0)$ & $0(0)$ & $2.3(0.4)$ & $97.6(0.4)$ \\
\hline \multirow[t]{2}{*}{$50 \%$} & $0.1(0)$ & $0(0)$ & $2.4(0.4)$ & $97.5(0.4)$ & $0(0)$ & $0(0)$ & $1.2(0.3)$ & $98.7(0.3)$ \\
\hline & \multicolumn{8}{|c|}{ Western Region } \\
\hline $15 \%$ & $24.9(1.2)$ & $2.3(1)$ & $20.5(1.3)$ & $52.3(1.1)$ & $20.7(1.1)$ & $1.9(0.9)$ & $22.6(1.3)$ & $54.8(1.1)$ \\
\hline $20 \%$ & $15.6(1)$ & $1.4(0.8)$ & $20.8(1.3)$ & $62.2(1.1)$ & $11.6(0.9)$ & $1.1(0.6)$ & $22(1.2)$ & $65.3(1.1)$ \\
\hline $25 \%$ & $8.9(0.8)$ & $0.8(0.5)$ & 19.2(1.1) & 71.1(1) & $5.8(0.6)$ & $0.6(0.4)$ & 19.1(1.1) & 74.5(1) \\
\hline $30 \%$ & $4.6(0.6)$ & $0.4(0.3)$ & $16.2(1)$ & $78.7(0.9)$ & $2.5(0.4)$ & $0.3(0.2)$ & $15(1)$ & $82.1(0.9)$ \\
\hline $35 \%$ & $2.2(0.3)$ & $0.2(0.2)$ & $12.6(0.8)$ & $85(0.8)$ & $1(0.2)$ & $0.1(0.1)$ & $10.8(0.8)$ & $88.1(0.8)$ \\
\hline $40 \%$ & $0.9(0.2)$ & $0.1(0.1)$ & 9.1(0.7) & $89.8(0.7)$ & $0.3(0.1)$ & $0.1(0)$ & $7.2(0.6)$ & $92.4(0.6)$ \\
\hline $45 \%$ & $0.4(0.1)$ & $0(0)$ & $6.2(0.5)$ & $93.4(0.5)$ & $0.1(0)$ & $0(0)$ & $4.4(0.4)$ & $95.4(0.4)$ \\
\hline \multirow[t]{2}{*}{$50 \%$} & $0.1(0)$ & $0(0)$ & $3.9(0.4)$ & $95.9(0.4)$ & $0(0)$ & $0(0)$ & $2.6(0.3)$ & $97.4(0.3)$ \\
\hline & \multicolumn{8}{|c|}{ Mid-Western Region } \\
\hline $15 \%$ & 25.2(1.2) & $2.6(1)$ & 18.4(1.4) & $53.8(1.1)$ & $20.9(1.2)$ & $2.2(0.9)$ & 19.8(1.4) & $57.1(1.1)$ \\
\hline $20 \%$ & 15.9(1.1) & $1.6(0.8)$ & $18.7(1.3)$ & $63.8(1.1)$ & $11.8(0.9)$ & $1.2(0.6)$ & $19.3(1.3)$ & 67.7(1.1) \\
\hline $25 \%$ & $9.2(0.8)$ & $0.9(0.5)$ & $17.2(1.2)$ & $72.7(1)$ & $5.9(0.7)$ & $0.6(0.4)$ & $16.7(1.1)$ & $76.8(1)$ \\
\hline $30 \%$ & $4.8(0.6)$ & $0.5(0.3)$ & $14.5(1)$ & $80.2(0.9)$ & $2.6(0.4)$ & $0.3(0.2)$ & 13(1) & $84.1(0.9)$ \\
\hline $35 \%$ & $2.3(0.3)$ & $0.2(0.2)$ & $11.2(0.9)$ & $86.3(0.8)$ & $1(0.2)$ & $0.1(0.1)$ & $9.2(0.8)$ & $89.6(0.8)$ \\
\hline $40 \%$ & $1(0.2)$ & $0.1(0.1)$ & 8.1(0.7) & $90.9(0.7)$ & $0.4(0.1)$ & $0(0)$ & $6(0.6)$ & $93.6(0.6)$ \\
\hline $45 \%$ & $0.4(0.1)$ & $0(0)$ & $5.4(0.5)$ & $94.2(0.5)$ & $0.1(0)$ & $0(0)$ & $3.6(0.4)$ & $96.3(0.4)$ \\
\hline \multirow[t]{2}{*}{$50 \%$} & $0.1(0)$ & $0(0)$ & $3.4(0.4)$ & $96.5(0.4)$ & $0(0)$ & $0(0)$ & $2(0.3)$ & $97.9(0.3)$ \\
\hline & \multicolumn{8}{|c|}{ Far-Western Region } \\
\hline $15 \%$ & 23.2(1.2) & $3.9(1.1)$ & $11.9(1.3)$ & $61(1.2)$ & 19.4(1.2) & $3(1)$ & 13.5(1.4) & 64.1(1.2) \\
\hline $20 \%$ & 14.5(1.1) & $2.4(0.8)$ & $12.2(1.3)$ & $70.9(1.1)$ & $10.8(0.9)$ & $1.6(0.7)$ & $13.2(1.3)$ & 74.4(1.1) \\
\hline $25 \%$ & $8.3(0.8)$ & $1.3(0.6)$ & $11.2(1.2)$ & $79.2(1)$ & $5.4(0.7)$ & $0.7(0.4)$ & 11.3(1.1) & $82.6(1)$ \\
\hline $30 \%$ & $4.3(0.6)$ & $0.6(0.4)$ & 9.3(1) & $85.8(0.9)$ & $2.3(0.4)$ & $0.3(0.2)$ & $8.6(1)$ & $88.8(0.9)$ \\
\hline $35 \%$ & $2(0.3)$ & $0.3(0.2)$ & $7(0.9)$ & 90.7 & $0.9(0.2)$ & $0.1(0.1)$ & $5.9(0.8)$ & 93.1(0.8) \\
\hline $40 \%$ & $0.9(0.2)$ & $0.1(0.1)$ & $4.9(0.7)$ & $94.2(0.7)$ & $0.3(0.1)$ & $0(0.1)$ & $3.7(0.6)$ & $96(0.6)$ \\
\hline $45 \%$ & $0.3(0.1)$ & $0(0)$ & $3.1(0.5)$ & $96.5(0.5)$ & $0.1(0)$ & $0(0)$ & $2.1(0.4)$ & $97.8(0.4)$ \\
\hline $50 \%$ & $0.1(0)$ & $0(0)$ & $1.9(0.4)$ & $98(0.4)$ & $0(0)$ & $0(0)$ & $1.1(0.3)$ & $98.9(0.3)$ \\
\hline
\end{tabular}

Note: $\mathrm{C} 2 \mathrm{C}=$ Catastrophic to Catastrophic; $\mathrm{C} 2 \mathrm{NC}=$ Catastrophic to non-catastrophic; $\mathrm{NC} 2 \mathrm{C}=$ Non-catastrophic to Catastrophic; NC2NC=Non-catastrophic to Non-Catastrophic 
Table 8: Stratification of Mobility across Place of Residence

\begin{tabular}{lllllllll}
\hline & \multicolumn{2}{l}{ Out of Pocket Expenses } & \multicolumn{5}{l}{ Medical Expenses } \\
& C2C & C2NC & NC2C & NC2NC & C2C & C2NC & NC2C & NC2NC \\
\cline { 2 - 8 } Threshold & Urban & & & & & & & \\
\hline $15 \%$ & $22.8(1.2)$ & $4.8(1)$ & $10.2(1.3)$ & $62.1(1.1)$ & $18.8(1.1)$ & $4.2(0.9)$ & $10.3(1.3)$ & $66.6(1.1)$ \\
$20 \%$ & $14.4(1)$ & $3(0.8)$ & $10.5(1.2)$ & $72.1(1.1)$ & $10.6(0.9)$ & $2.4(0.6)$ & $10.2(1.2)$ & $76.8(1.1)$ \\
$25 \%$ & $8.3(0.8)$ & $1.7(0.5)$ & $9.7(1.1)$ & $80.3(1)$ & $5.3(0.6)$ & $1.2(0.4)$ & $8.8(1.1)$ & $84.7(1)$ \\
$30 \%$ & $4.3(0.6)$ & $0.9(0.3)$ & $8(1)$ & $86.7(0.9)$ & $2.4(0.4)$ & $0.6(0.2)$ & $6.6(0.9)$ & $90.4(0.9)$ \\
$35 \%$ & $2.1(0.3)$ & $0.4(0.2)$ & $6.1(0.8)$ & $91.4(0.8)$ & $0.9(0.2)$ & $0.2(0.1)$ & $4.5(0.8)$ & $94.3(0.8)$ \\
$40 \%$ & $0.9(0.2)$ & $0.2(0.1)$ & $4.2(0.7)$ & $94.7(0.7)$ & $0.3(0.1)$ & $0.1(0)$ & $2.8(0.6)$ & $96.8(0.6)$ \\
$45 \%$ & $0.3(0.1)$ & $0.1(0)$ & $2.7(0.5)$ & $96.9(0.5)$ & $0.1(0)$ & $0(0)$ & $1.5(0.4)$ & $98.3(0.4)$ \\
$50 \%$ & $0.1(0)$ & $0(0)$ & $1.6(0.4)$ & $98.2(0.4)$ & $0(0)$ & $0(0)$ & $0.8(0.3)$ & $99.2(0.3)$ \\
\hline & Rural & & & & & & & \\
\hline $15 \%$ & $25.1(1.2)$ & $2.2(1)$ & $19.6(1.3)$ & $53.1(1.1)$ & $20.8(1.1)$ & $1.8(0.9)$ & $20.9(1.3)$ & $56.4(1.1)$ \\
$20 \%$ & $15.8(1)$ & $1.3(0.8)$ & $19.9(1.2)$ & $63(1)$ & $11.7(0.9)$ & $1(0.6)$ & $20.3(1.2)$ & $67(1)$ \\
$25 \%$ & $9(0.8)$ & $0.7(0.5)$ & $18.3(1.1)$ & $71.9(1)$ & $5.8(0.6)$ & $0.5(0.4)$ & $17.6(1.1)$ & $76.1(1)$ \\
$30 \%$ & $4.7(0.6)$ & $0.4(0.3)$ & $15.4(1)$ & $79.5(0.9)$ & $2.6(0.4)$ & $0.2(0.2)$ & $13.7(0.9)$ & $83.5(0.9)$ \\
$35 \%$ & $2.2(0.3)$ & $0.2(0.2)$ & $11.9(0.8)$ & $85.7(0.8)$ & $1(0.2)$ & $0.1(0.1)$ & $9.7(0.8)$ & $89.2(0.8)$ \\
$40 \%$ & $1(0.2)$ & $0.1(0.1)$ & $8.6(0.7)$ & $90.4(0.7)$ & $0.3(0.1)$ & $0(0)$ & $6.4(0.6)$ & $93.3(0.6)$ \\
$45 \%$ & $0.4(0.1)$ & $0(0)$ & $5.8(0.5)$ & $93.8(0.5)$ & $0.1(0)$ & $0(0)$ & $3.8(0.4)$ & $96(0.4)$ \\
$50 \%$ & $0.1(0)$ & $0(0)$ & $3.6(0.4)$ & $96.2(0.4)$ & $0(0)$ & $0(0)$ & $2.2(0.3)$ & $97.8(0.3)$ \\
\hline
\end{tabular}

Note: $\mathrm{C} 2 \mathrm{C}=$ Catastrophic to Catastrophic; $\mathrm{C} 2 \mathrm{NC}=$ Catastrophic to non-catastrophic; $\mathrm{NC} 2 \mathrm{C}=$ Non-catastrophic to Catastrophic; NC2NC=Non-catastrophic to Non-Catastrophic

Table 6 shows mobility of households for catastrophic health expenditure across various ethnicity categories as classified by Government of Nepal. The highest percentages of households that remain in the state of catastrophic health expenditure are from Disadvantaged non-dalit tarai castes and religious minorities. In the same vein, the highest percentages of households from these ethnicity groups suffer from catastrophic health expenditure even though they were not a sufferer of catastrophic health expenditure in earlier time period. Relatively fewer percentages of households belonging to relatively advantaged janjaties and upper caste groups were in catastrophic to catastrophic and non-catastrophic to catastrophic movement. The highest percentages of households move from catastrophic to non-catastrophic health expenditure between two periods for relatively advantaged janajaties. Table 6 shows mobility across five geographic regions. Movement from catastrophic to catastrophic is similar among the five geographical regions. However, transition from one stage to another is remarkably different. Far-western region and central region shows that the highest percentages of households are moving from catastrophic health expenditure to non-catastrophic health expenditure between two survey periods. Similarly, movement from non-catastrophic to catastrophic health expenditure is the highest in western and mid-western regions. Rural households (table 8) are in higher percentages that 
remain in catastrophic health expenditure in two survey periods. Similarly, greater percentages of households also transit from non-catastrophic to catastrophic health expenditure in rural area.

\section{DISCUSSION}

The paper, for the first time in the literature, provided estimates of mobility of households for catastrophic health expenditure between independent cross-section surveys. Majority of households remained in the non-catastrophic state in both periods. A second majority of households remained in the state of catastrophic health expenditure in both survey periods which indicates that catastrophichealth expenditure is still a chronic phenomenon at country level. Transition from one state to another was also noticed among significant percentages of households. In this case flow from catastrophic to non-catastrophic state is lower than non-catastrophic to catastrophic state which indicates that in seven-year period, more and more households moving into catastrophic health expenditure state in later survey year. Stratified analysis further provides evidences about the mobility in specific subgroup of population. Households in the tarai region tended to remain in the state of catastrophic health expenditure as compared to those in other ecological regions. Ethnic groups such as ethnic minorities and disadvantaged tarai caste group households showed relatively higher tendency to remain either in catastrophic health expenditure in both periods or transit to catastrophic health expenditure in later year regardless of their state in first period. Similarly, rural households also exhibit similar tendency. These findings provide policy makers the evidences about the performance of current policy to decrease financial burden for health expenditure.

To effectively monitor and track the achievements in UHC WHO recommended to monitor the households that escape catastrophic health expenditure as well as those that remain in or fall back into the catastrophic health expenditure. The method proposed in this paper attempts to address this problem which was ideally expected to be achieved only by panel data. This paper utilizes the methodology to create synthetic panel data proposed by Dang and Lanjouw (2013) which was developed by The World Bank to estimate the poverty dynamics. The methodology has been slightly modified to accommodate the specific characteristics of health expenditure data. The linear regression model in the original method is replaced with a Two Part Fractional Response Model which better suits the share of health expenditure data as a percent of non-food consumption. The cross-section survey are widely available at country level. Using this methodology, cross-section survey can be readily used to provide the point estimate of household level mobility for catastrophic health expenditure between two survey periods. 
Our approach to estimate the mobility using synthetic panel has some limitations and pitfalls that need close scrutiny for the validity of results. We used non-food consumption to estimate the value $P$ which is later used to create the synthetic panel for share of health expenditure as a percentage of non-food consumption. The latter is the ratio of health expenditure and non-food consumption. Grossman (2000) considered illness as random event, therefore, health expenditures are also random phenomena. So, illness for households is more or less uncorrelated between two periods. So, most of the correlation for the ratio of health expenditure and non-food consumption is carried over by the non-food consumption. Therefore, we used non-food consumption to estimate the value of $P$. Similarly, we used time invariant household characteristics to predict the health expenditure share which provides only a fair fitness of the model. It is generally difficult to get a list of time invariant household characteristics that explain a greater percentage of variation in share of health expenditure. Further research and methodological refinement is needed to improve the model fitness which has impact-upon the precision of model estimates.

The paper reports that chronic nature of catastrophic health expenditure at national level which requires special attention for the policy makers. Similarly, greater percentages of households are transiting to catastrophic state in later year indicates that households are falling into catastrophic health expenditure in the later year. Higher percentage of households having catastrophic health expenditure state in later year in specific subgroups indicates special policy measures to address the gap. This paper is expected to contribute to both on empirical estimates and methodological aspect to estimate the welfare impact of health expenditure using available cross-section data which was ideally expected to be achieved only by panel data. The methodology proposed by theDang and Lanjouw (2013) can be extended with some contextual modifications as discussed. Further improvement in the method can be pivotal to monitoring UHC policies in developing countries.

\section{CONCLUSIONS}

Movement into and out of catastrophic payments is variable of interest after introduction of FHCS. The study measures dynamics of catastrophic payment before and after introduction of FHCS by utilizing recently developed method of creating synthetic panel from two cross-sectional data. It is interested to estimate percentage of households that faced catastrophic health expenditure in first period but didn't face catastrophic health expenditure in second period. Catastrophic payment is defined as OOP payments as a share of total non-food consumption. The threshold for catastrophic health expenditure for non-food expenditure has been set 15\% to 50\%. Probability of percentage population faced catastrophic impact due to medicine costs in the first period and in the second period $(\mathrm{C} 2 \mathrm{C})$ is decreasing from 20.1 per cent to 0.01 per cent 
as increased in threshold $15 \%$ to $50 \%$. Similarly, probability of catastrophic impact in the first period but not in the second period (C2NC) is decreasing from 3.1 per cent to 0.00 per cent as increased in threshold 15\% to 50\%. Probability of not having catastrophic impact in the first period but catastrophic impact in the second period (NC2C) is decreasing from 17.2 per cent to 1.9 per cent as increased in threshold $15 \%$ to $50 \%$. Probability of not having catastrophic impact in both periods (NC2NC) is increasing from 60.0 per cent to 98.3 per cent as increased in threshold $15 \%$ to $50 \%$. C2C incidences in Terai ecological belt are higher than in hills and Mountain. Similarly, Disadvantaged non Dalit Terai caste have higher incidence than other caste groups. Synthetic panel gives the indicative trends; incidences may not be directly comparable with incidences estimated from cross-sectional data.

These movements have been explained with reference to the total consumption and non-food consumption, and for OOP payments and payments for medicine only. At 10 $\%$ threshold, 13\% households faced catastrophic health expenditure in both periods. While only 5\% households get out of catastrophic expenditure in the second period. Nearly $30 \%$ households were found not suffering catastrophic health expenditure in 2003 but faced catastrophic health expenditure in second period. More than 52\% of $\mathrm{HH}$ didn't face catastrophic health expenditure in both periods.

\section{References}

Adhikari, S. R., Maskay, N. M., \& Sharma, B. P. (2009). Paying for hospital-based care of Kala-azar in Nepal: assessing catastrophic, impoverishment and economic consequences. Health policy and planning, 24(2), 129-139.

Banks, J., Blundell, R., \& Brugiavini, A. (2001). Risk pooling, precautionary saving and consumption growth. The Review of Economic Studies, 68(4), 757-779.

Berki, S. (1986). A look at catastrophic medical expenses and the poor. Health Affairs, $5(4), 138-145$.

Boerma, T., Eozenou, P., Evans, D., Evans, T., Kieny, M.-P., \& Wagstaff, A. (2014). Monitoring progress towards universal health coverage at country and global levels.

Dang, H.-A., \& Lanjouw, P. (2013). Measuring poverty dynamics with synthetic panels based on cross-sections. World Bank Policy Research Working Paper(6504).

Deaton, A. (1985). Panel data from time series of cross-sections. Journal of econometrics, 30(1), 109-126.

Deaton, A., \& Paxson, C. (1993). Intertemporal choice and inequality. National Bureau of Economic Research. 
Gertler, P., \& Gruber, J. (1997). Insuring consumption against illness: National Bureau of Economic Research.

Grossman, M. (2000). The human capital model. Handbook of health economics, 1, 347408.

Kenkel, B. (2012). pbivnorm: Vectorized bivariate normal cdf. URL http://CRAN. R-project. org/package= pbivnorm, 0.5-1.

Naga, R. H. A., \& Lamiraud, K. (2011). Catastrophic health expenditure and household well-being.

Ramalho, E. A., Ramalho, J. J., \& Murteira, J. M. (2011). Alternative estimating and testing empirical strategies for fractional regression models. Journal of Economic Surveys, 25(1), 19-68.

Van Doorslaer, E., O'Donnell, O., Rannan-Eliya, R. P., Somanathan, A., Adhikari, S. R., Akkazieva, B., ... Huq, M. N. (2005). Paying out-of-pocket for health care in Asia: Catastrophic and poverty impact. Erasmus University, Rotterdam and IPS, Colombo.

Van Doorslaer, E., O'Donnell, O., Rannan-Eliya, R. P., Somanathan, A., Adhikari, S. R., Garg, C. C., . . Ibragimova, S. (2007). Catastrophic payments for health care in Asia. Health economics, 16(11), 1159-1184.

Verbeek, M. (2008). Pseudo-panels and repeated cross-sections The Econometrics of Panel Data (pp. 369-383): Springer

Wagstaff, A. (2007). The economic consequences of health shocks: Evidence from Vietnam. Journal of health economics, 26(1), 82-100. 


\section{Appendix}

\section{Annex-I: Two part model}

Table 1: Two part model for share of health expenditure as a percentage of nonfood consumption (2010/2011)

\begin{tabular}{llll|lll}
\hline Y & \multicolumn{2}{l|}{$\begin{array}{l}\text { OOP Share (zero/other than } \\
\text { zero) }\end{array}$} & & & \multicolumn{2}{l}{ OOP Share >0 } \\
\hline Covariates & Estimate & Std. Err & & Estimate & Std. Err. \\
\hline Male & 0.088 & 0.065 & & -0.508 & 0.068 & $* * *$ \\
Hill & -0.621 & 0.068 & $* * *$ & -0.247 & 0.082 & $* * *$ \\
Mountain & -0.423 & 0.135 & $* * *$ & 0.012 & 0.164 & \\
Central Region & -0.152 & 0.082 & $*$ & -0.213 & 0.091 & $* *$ \\
Eastern Region & -0.089 & 0.085 & & -0.322 & 0.095 & $* * *$ \\
Far Western Region & -0.370 & 0.126 & $* * *$ & -0.478 & 0.153 & $* * *$ \\
Mid-western & 0.232 & 0.103 & $* *$ & -0.349 & 0.109 & $* * *$ \\
Urban & -0.154 & 0.073 & $* *$ & -0.583 & 0.088 & $* * *$ \\
Advantaged caste & -0.087 & 0.070 & & -0.537 & 0.083 & $* * *$ \\
R-Squared & 0.035 & & & R-Squared & 0.04 & \\
N & 4166 & & & $\mathbf{N}$ & 1641 & \\
\hline
\end{tabular}

Table 2: Two part model for share of health expenditure as a percentage of nonfood consumption (2003/2004)

\begin{tabular}{llll|llc}
\hline Y & \multicolumn{2}{l}{$\begin{array}{l}\text { OOP } \\
\text { than zhare }\end{array}$} & (zero/other & Y & \multicolumn{2}{l}{ OOP Share $>$ 0 } \\
\hline Covariates & Estimate & Std. Err & & Estimate & Std. Err. \\
\hline Male & -0.260 & 0.087 & $* * *$ & -0.484 & 0.115 & $* * *$ \\
Hill & -0.730 & 0.088 & $* * *$ & -0.889 & 0.148 & $* * *$ \\
Mountain & -1.060 & 0.179 & $* * *$ & -0.659 & 0.426 & \\
Central Region & 0.065 & 0.101 & & -0.467 & 0.136 & $* * *$ \\
Eastern Region & -0.189 & 0.112 & $*$ & -0.473 & 0.132 & $* * *$ \\
Far Western Region & -0.062 & 0.173 & & -1.032 & 0.312 & $* * *$ \\
Mid-western & -0.365 & 0.146 & $* *$ & -0.530 & 0.196 & $* * *$ \\
Urban & -0.157 & 0.098 & & -0.512 & 0.188 & $* * *$ \\
Advantaged caste & -0.046 & 0.090 & & -0.629 & 0.163 & $* * *$ \\
R-Squared & 0.023 & & & R-Squared & 0.071 & \\
N & 2769 & & & N & 852 & \\
\hline
\end{tabular}

